\section{Sisters doing it for themselves}

I was interested to read the commentary by Anne Szarewksi describing how to individually tailor a woman's combined oral contraceptive (COC) regimen to minimise the amount of breakthrough bleeding she has to experience each year. ${ }^{1}$ However, in view of the article on repeat abortion (Das et al.) in the same issue of the journal, should we not be more concerned in preventing pregnancy in COC users?? $?^{2}$ Das et al. state that $35 \%$ of first attenders were using COC and 55\% at repeat abortion.

It is not uncommon to see patients who have become pregnant on the COC pill despite taking it without fault, some patients unfortunately on more than one occasion, having been restarted on their original COC following the end of their pregnancy. These failures of the method could be attributed to the individual woman ovulating as a 7-day pill-free interval is too long for her ovaries to remain quiescent. In view of this, a $24 / 4$ regimen should be the norm but the drug companies seem slow to change their products. Several alternative formulations such as $24 / 4$ or continuous-use pill regimens are available in other countries including the USA and Australia, but none are currently available in the UK, although one has been granted a licence here with a launch date awaited. ${ }^{3}$ This will no doubt come at a price. Surely all the COC manufacturers should provide a product that is more effective? However, I am sure that the need for a further licence to enable a change to a $24 / 4$ formulation for the cheaper generic COCs would make drug companies reluctant. We can never be certain which patients fall pregnant despite full compliance with the COC taking 'rules' - what is certain is that there will be some women whom this affects each year, and they are likely to be young, new pill starters. This seems awfully unfair on them when in this day and age we have the knowledge to prevent these unwanted pregnancies.

Emily Gwinnell, MBBS, MRCGP

Clinical Assistant, Contraceptive and

Reproductive Healthcare, Ashwood Centre,

St Marys Hospital, Kettering, UK.

E-mail: emilygwinnell@doctors.org.uk

References

Szarewski A. Sisters doing it for themselves. J Fam Plann Reprod Health Care 2009; 35: 71-72.

Das S, Adegbenro A, Ray S, Amu O. Repeat abortion: facts and issues. J Fam Plann Reprod Health Care 2009; 35: 93-95.

3 Personal communication with Bayer HealthCare. Also see Bayer HealthCare News Release at http://www. yaz.com/html/pdf/2008-0398E-YAZ-Lauch Europa.pdf [Accessed 15 April 2009].

\section{Sisters doing it for themselves}

Our sisters may tailor their combined oral contraceptive (COC) use to reduce their frequency of menstrual bleeds; however, as their responsible elder siblings we have a duty to ensure they make an informed lifestyle choice.

The benefits of a reduction in menstrual bleeds and premenstrual symptoms must be weighed against the lack of any data about the long-term safety of the COC taken continuously. All current knowledge about health risks and benefits of COC use is based on long-term studies of women taking the pill for 21 days in each 28day cycle. We cannot assume the same benefits (or risks) will apply if the COC is taken continuously.

\section{Gillian Robinson, FRCOG, FFSRH}

Associate Specialist, Sexual Health, Southwark Primary Care Trust, London, UK. E-mail: gillian.robinson@southwarkpct.nhs.uk

\section{Reference}

Szarewski A. Sisters doing it for themselves. J Fam Plann Reprod Health Care 2009; 35: 71-72.

\section{Reply}

I agree entirely with Dr Robinson ${ }^{1}$ that that longterm health effects of longer-cycle combined oral contraceptive (COC) use have not been formally studied for more than a few years and we should ensure that monitoring continues. However, we should remember that monthly bleeding is in fact not the norm for healthy, reproductive age women. As Thomas et al. have pointed out: "in hunter-gatherer times, women had infrequent menstruations because they had closely spaced pregnancies, they breastfed their infants for long intervals (which suppresses ovulation and menstruation), and they died before reaching menopause. Prehistoric women had as few as 50 menstruations per lifetime, whereas the modern woman has approximately 450 bleeding episodes". 2 In addition, the bleeding that occurs during the pill-free interval is simply due to hormone withdrawal, not to any physiological need. The studies of longer cycle/continuous pilltaking regimens have so far not given any indication that the adverse event or metabolic profile of extended-regimen oral contraceptives differs in any clinically significant manner from traditional 28-day regimens, while having many health benefits. ${ }^{3}$. Indeed, even a Cochrane Collaboration review in 2005 concluded that "continuous dosing of COCs is a reasonable approach for women without contraindications to COCs". 4

\section{Anne Szarewski, PhD, FFSRH}

Clinical Consultant and Honorary Senior Lecturer, Cancer Research UK Centre for Epidemiology, Mathematics and Statistics, Wolfson Institute of Preventive Medicine, London, UK, and Editor-in-Chief, Journal of Family Planning and Reproductive Health Care. E-mail:a.szarewski@qmul.ac.uk

\section{References}

Robinson G. Sisters doing it for themselves (Letter) $J$ Fam Plann Reprod Health Care 2009: 35: 205.

Thomas S, Ellerton C. Nuisance or natural and healthy: should monthly menstruation be optional for women? Lancet 2000; 355: 922-92 3 Sulak P. Continuous oral contraception: changing 355-374.

4 Edelman AB, Gallo MF, Jensen JT, Nichols MD, Schulz $\mathrm{KF}$, Grimes DA. Continuous or extended cycle versus cyclic use of combined oral contraceptives for contraception (Review). Cochrane Database Syst Rev

\section{Genuine Depo-Provera ${ }^{\circledR}$ failure}

After reading the case report of Lucinda Farmer and Elizabeth Patel entitled 'Contraceptive failure of Depo-Provera ${ }^{\circledR}$ : long-acting reversible contraceptive (LARC) methods do fail too' in the January 2009 issue of this Journal ${ }^{1}$ we would like to report a case of genuine Depo-Provera failure. Recently, a 23-year-old girl came to our family planning clinic with abdominal pain, breast tenderness, nausea, vomiting and tiredness of and on for 1 week. The patient was fit and healthy, with a body mass index (BMI) of 19, was a light smoker and normotensive.

The patient had used Injection DepoProvera ${ }^{\circledR}$ from age 15 to 21 years and had been very happy with this method. She started DepoProvera on 19 November 2008 on the second day of her cycle at her general practitioner's surgery and received the injection in her buttock. She had another injection at the same surgery 12 weeks later on 11 February 2009. She had one episode of bleeding for 3 days, which began on 18 January 2009.

On history and examination she demonstrated symptoms of pregnancy, and bimanual examination showed an anteverted 8 week-sized uterus with no cervical excitation or tenderness. Both adnexa were clear. A pregnancy test was positive and she opted for termination of pregnancy. Her gestation was 9 weeks 4 days by ultrasound scan.

We would like to highlight that failures can still occur with perfect use of Depo-Provera. Although current Faculty of Sexual and Reproductive Healthcare (FSRH) and National Institute for Health and Clinical Excellence (NICE) guidance mention a low failure rate (i.e. 4 in 1000 over 2 years) for the progestogen-only inject able given in accordance with the licensed use of every 12 weeks plus 5 days, higher failure rates with typical use up to $7 \%$ were found in the study of Kost et al. ${ }^{2}$

Pregnancy should be always considered in women presenting with appropriate symptoms, even when Depo-Provera has been given regularly within the licensed use.

We agree with the suggestion of Drs Farmer and Patel that delayed diagnosis of an unplanned pregnancy could result in delay in seeking either abortion care or antenatal care.

Soe Nyunt Aung, MRCOG, DFSRH Speciality Doctor, NHS Hull, Hull, UK E-mail: soenyunt.aung@hullpct.nhs.uk

Marian Everett, MBChB, FFSRH

Consultant in Sexual and Reproductive Health, NHS Hull, Hull, UK

\section{References}

Farmer L, Patel E. Contraceptive failure of DepoProvera ${ }^{\circledR}$ : long-acting reversible contraceptive (LARC) methods do fail too. J Fam Plann Reprod Health Care 2009; 35: 59-60.

Kost K, Singh S, Vaguhan B, Trussell J, Bankole A. Estimates of contraceptive failure from the 2002 National Survey of Family Growth. Contraception National Survey

IUS as emergency contraception

I read with interest the article by Moss et al. ${ }^{1}$ in the April 2009 issue of the journal about the understanding of intrauterine contraception by obstetric and gynaecology trainees.

I would question some of the article's conclusions. Without publishing the list of 'correct answers' it is not possible to know how I would have been rated on some of the questions. In particular 'An IUS is effective as emergency contraception' I would certainly have answered in the affirmative.

We all know that the intrauterine system (IUS) is not licensed as emergency contraception (EC) and never will be because of its cost, but if it were being planned as the ongoing method of contraception, it would certainly be effective as EC.

The postcoital intrauterine device (IUD) is not relying on its copper content for its efficacy. The copper inhibits sperm mobility and the ability to fertilise the ovum. When it is fitted after sex, it is relying only on its ability to prevent implantation. Therefore any IUD would be effective, including the IUS. It therefore follows that it would be safe to fit the IUS on any day up to the estimated time of possible implantation Day 19 in a 28-day cycle. It would not of course be the ideal time in the cycle, but might well prevent an unplanned pregnancy in a patient where you are not certain that she will return at a more ideal time.

Beth Devonald, MRCGP, LoC IUT Associate Specialist Gynaecology, Lincoln County Hospital, Lincoln, UK.

E-mail:devonald@btinternet.com

Reference

Moss E, Reynolds T, Williams D, Redman C Obstetrics and gynaecology trainees' understanding of Reprod Reprod Health Care 2009; 35: 97-100.

\section{Reply}

The Clinical Effectiveness Unit (CEU) would like to refute the suggestion in Dr Devonald's letter ${ }^{1}$ that the levonorgestrel-releasing intrauterine system (LNG-IUS, Mirena ${ }^{\circledR}$ ) can be used for emergency contraception (EC). There is no evidence that the LNG-IUS is effective as EC and it is not licensed for such use. 